\title{
Design and Construction of a Distributed Sensor NET for Biotelemetric Monitoring of Brain Energetic Metabolism using Microsensors and Biosensors
}

\author{
Pier Andrea Serra, Giulia Puggioni, Gianfranco Bazzu, Giammario Calia, \\ Rossana Migheli and Gaia Rocchitta \\ University of Sassari \\ Italy
}

\section{Introduction}

Neurochemical pathways involved in brain physiology or disease pathogenesis are mostly unknown either in physiological conditions or in neurodegenerative diseases. Nowadays the most frequent usage for biotelemetry is in medicine, in cardiac care units or step-down units in hospitals, even if virtually any physiological signal could be transmitted (FCC, 2000; Leuher, 1983; Zhou et al., 2002). In this chapter we present a wireless device connected with microsensors and biosensors capable to detect real-time variations in concentrations of important compounds present in central nervous system (CNS) and implicated in brain energetic metabolism (Bazzu et al., 2009; Calia et al., 2009).

Molecular Oxygen $\left(\mathrm{O}_{2}\right)$, an essential molecule for life, is utilized not only for cellular respiration but also for biosynthesis and metabolism of various important biomolecules such steroids, eicosanoids and neuroactive substances (Watanabe et al., 1997). It is also implicated in several biochemical reactions involving, for instance, ATP in the brain (Bazzu et al., 2009). To monitor istantaneous oxygen concentrations and relative variations could give important information about brain energetic metabolism related to glucose (Fillenz, 2005) or lactate consumption (Aubert et al., 2005). Eletrochemical reduction of oxygen is amperometrically obtained by means of complex transformations occurring at a carbonepoxy sensor surface by applying a potential of $-400 \mathrm{mV} v \mathrm{sg} / \mathrm{AgCl}$ reference electrode (RE) (Bazzu et al., 2009; Calia et al., 2009) as follows:

$$
\begin{gathered}
\mathrm{O}_{2}+2 \mathrm{H}^{+}+2 \mathrm{e}^{-} \rightarrow \mathrm{H}_{2} \mathrm{O}_{2} \\
\mathrm{H}_{2} \mathrm{O}_{2}+2 \mathrm{H}^{+}+2 \mathrm{e}^{-} \rightarrow 2 \mathrm{H}_{2} \mathrm{O}
\end{gathered}
$$

Because of its anatomical characteristics and physiology, the central nervous system (CNS) is assumed to be particularly sensitive to oxidative stress (Emerit et al., 2005). Oxidative stress in CNS is now known as responsible for involvement of reactive oxygen species (ROS) and reactive nitrogen species (RNS). This particular kind of stress is crucial for the modulation of fundamental cellular functions as apoptosis, calcium mobilization, ion 
transport and all phenomena involved in excitotoxicity (Emerit \& Edeas, 2005). Oxidative stress takes place from a disparity, involving the physiological antioxidant capability and free radicals synthesis (Andersen, 2004), so the dynamics concerning antioxidants in CNS are extremely important.

Ascorbic acid (AA) is the most important component of antioxidant pool in the brain (Serra et al., 2002). Low molecular weight antioxidant AA is a water soluble vitamin that owns radical scavenger properties against ROS and RNS (Serra et al., 2002). As it is not produced in human organism but introduced with diet (Hediger, 2002), the presence of a specific transporter (SVCT2) allows its cytosolic internalization in neurons. Ascorbic acid is readily oxidized to dehydroascorbate (DHAA) which can undergo irreversible hydrolysis to 2,3diketo-L-gulonic acid, but because of its crucial role in CNS, DHAA is easily converted to the reduced form for preventing vitamin $\mathrm{C}$ depletion. AA is as well implicated in the protection against excitotoxicity due to high glutamate concentration through ascorbateglutamate hetero-exchange (Rice, 2000). Ascorbic acid is readily oxidized on epoxy-carbon electrode surface at $+120 \mathrm{mV}$ against $\mathrm{Ag} / \mathrm{AgCl}$ as follows:

$$
\text { L-Ascorbic acid }(+120 \mathrm{mV}) \rightarrow \text { DHAA }+2 \mathrm{e}^{-}+2 \mathrm{H}^{+}
$$

Several biologically interesting compounds are not directely oxidizable at a sensor surface, in this case it is needed a biosensor (Pantano et al., 1995). Biosensor combines a trasducer with an enzyme that is capable to give sensitivity and selectivity to the device (Scheller et al., 1997).

Glucose (GLU) is actively involved in ATP synthesis and its concentration in extracellular spaces is the most important factor for energetic metabolism (Lowry et al., 1998; Magistretti et al., 1999, Fillenz et al., 2005). GLU detection is possible by means of loading on a Pt surface transducer glucose oxidase (GOx) enzyme. GOx is covalently linked with flavin adenine dinucleotide (FAD) (Serra et al., 2007) and is extremely reliable because of its good sensitivity to the enzyme substrate and high stability when immobilized on Pt electrodes by means of poly-orthophenylenediamine (OPD) (Wilson et al., 1992; Lowry et al., 1998). The biosensor-based detection of GLU occurs as follows:

$$
\begin{gathered}
\beta \text {-D-Glucose }+ \text { FAD }^{+}-\mathrm{GOx} \rightarrow \text { D-Glucono- } \delta \text {-Lactone }+\mathrm{FADH}_{2}-\mathrm{GOx} \\
\text { FADH }_{2}-\mathrm{GOx}+\mathrm{O}_{2} \rightarrow \mathrm{FAD}^{+}-\mathrm{GOx}+\mathrm{H}_{2} \mathrm{O}_{2}
\end{gathered}
$$

As glucose, lactate (LAC) is an important molecule involved in brain energetic metabolism as product of glicolysys (Fillenz, 2005) or energetic substrate for neurons (Magistretti et al., 1999). LAC is oxidized by lactate oxidase (LOx), an enzyme with a covalently-linked FAD cofactor (Serra et al., 2007). After the oxidation of the substrate, the further oxidation of $\mathrm{FADH}_{2}$ to $\mathrm{FAD}^{+}$produces $\mathrm{H}_{2} \mathrm{O}_{2}$ in the presence of $\mathrm{O}_{2}$.

$$
\begin{gathered}
\text { L-Lactate }+\mathrm{FAD}^{+}-\mathrm{LOx} \rightarrow \text { Pyruvate }+\mathrm{FADH}_{2}-\mathrm{LOx} \\
\mathrm{FADH}_{2}-\mathrm{LOx}+\mathrm{O}_{2} \rightarrow \mathrm{FAD}^{+}-\mathrm{LOx}+\mathrm{H}_{2} \mathrm{O}_{2}
\end{gathered}
$$

The application of a positive potential $(+700 \mathrm{mV}$ vs $\mathrm{Ag} / \mathrm{AgCl})$ to a $\mathrm{Pt}$ working electrode generates a current proportional to the concentration of the $\mathrm{H}_{2} \mathrm{O}_{2}$. Reactions occur as follows:

$$
\mathrm{H}_{2} \mathrm{O}_{2} \rightarrow \mathrm{O}_{2}+2 \mathrm{e}^{-}+2 \mathrm{H}^{+}
$$


where the amount of current produced by the previous oxidation (8) is proportional to the quantity of substrate (GLU or LAC) transformed by the enzyme. The intrinsic chemical characteristics of each indicated molecule allow using specific telemetric devices able to work in oxidation mode (Calia et al., 2009) or in reduction mode (Bazzu et al., 2009; Calia et al., 2009). In this chapter we describe the implementation of a distributed biosensor NET, composed by implantable biotelemetry devices and derived from previously published systems (Bazzu et al., 2009; Calia et al., 2009), successfully used in conjunction with microbiosensors for the in-vivo measurement of brain $\mathrm{O}_{2}, \mathrm{AA}$, glucose and lactate. The analysis of signals derived from the above sensors allowed the real-time study of biochemical pathways involved in brain energetic metabolism. The design, construction and operation of the hardware, firmware and software are described. The proposed system, based on simple and inexpensive components, could be used as a rapid and reliable model for the real-time study of the effects of different drugs on brain neurochemicals and offers the possibility of expanding the biotelemetric NET simply and quickly.

\section{Biotelemetric system hardware}

The electronic circuit of the implantable biotelemetric device (Fig. 1) was built using surface mount components and comprised two different parts: the amperometric module and the microcontroller/transceiver module.

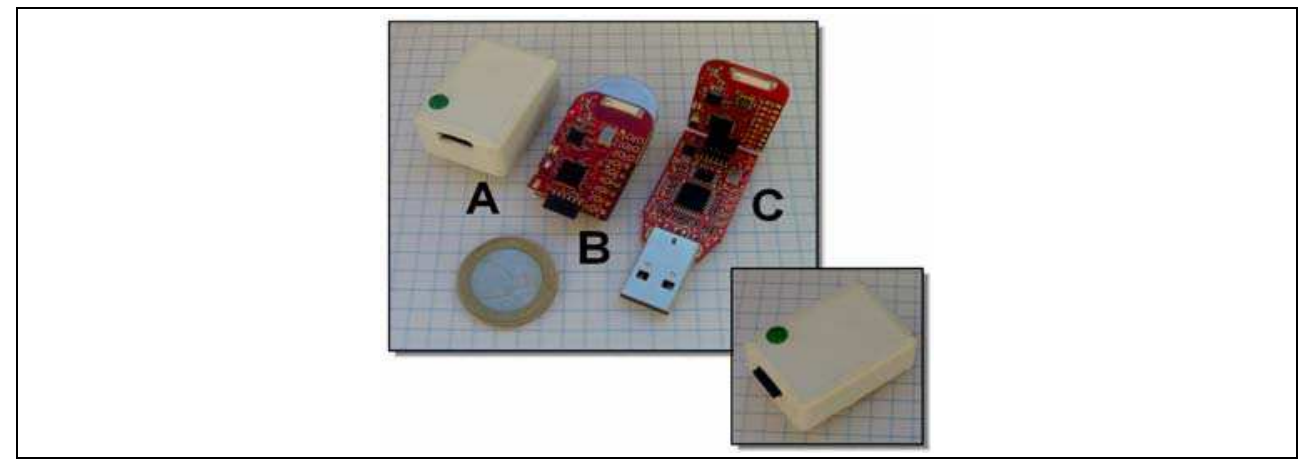

Fig. 1. Pictures showing the biotelemetry system developed during this study (see text).

As schematized in figures 2 and 3, the amperometric module was made soldering a quad operational amplifier (MCP6042), a Zener diode (ZXRE4001), two resistors, a potentiomenter and one capacitor on a $28 \mathrm{~mm} \times 17 \mathrm{~mm}$ PCB. The MCP6042 can operate from a single-supply voltage with "rail-to-rail" inputs and outputs; it has been designed for micropower applications consuming only $600 \mathrm{nA}$ per OPA with low input bias current (1 $\mathrm{pA})$ and high input resistance $\left(>10^{13} \Omega\right)$.

The zener diode plays a pivotal role in the amperometric circuitry; as bandgap voltage reference, it generates a fixed voltage $\left(\mathrm{V}_{\mathrm{z}}=1.22 \mathrm{~V}\right)$ consuming around $10 \mu \mathrm{A}$ in virtue of a limiting resistance $(150 \mathrm{~K})$.

The not inverting input of the potentiostat was connected to $\mathrm{V}_{\mathrm{z}}$ (Bazzu et al., 2009; Calia et al., 2009) for working with $\mathrm{O}_{2}$ microsensors (reduction mode, Fig. 2).

In oxidation mode (Fig. 3), the above mentioned input of the potentiostat was grounded resulting in a positive potential applied to working electrode (WE) ranging from ground 


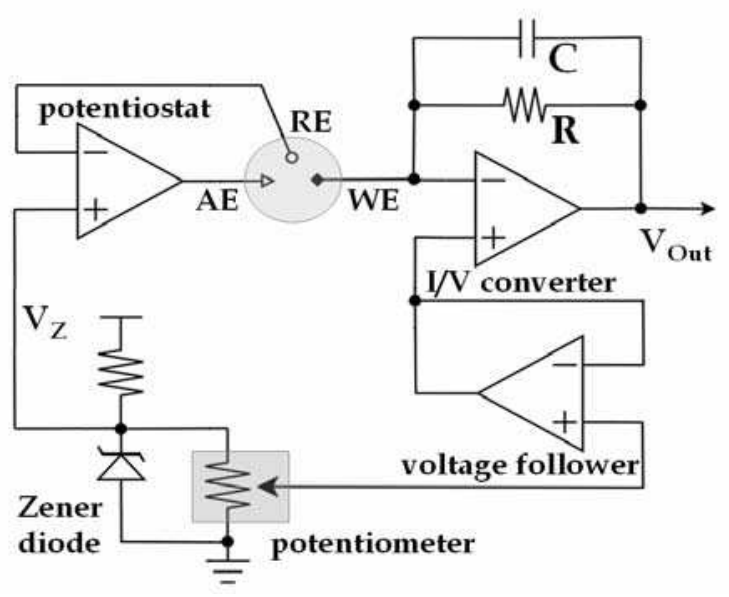

Fig. 2. Schematic of the amperometric module of the biotelemetric device working in "reduction mode".

(GND) to $\mathrm{V}_{\mathrm{z}}$. The inverting input of the potenziostat was directly connected to RE while its output wired to the auxiliary (AE) electrode. This allows the implementation of a feedback circuit in which RE and AE potentials are maintained at the same potential of the notinverting input (potentiostatic circuit).

The buffered voltage divider, composed by the potentiomenter and the voltage follower, generated the potential necessary to polarize the $W E$ in a range comprised between 0 and $1.22 \mathrm{~V}\left(\mathrm{~V}_{\mathrm{z}}\right.$, controlled by ZXRE4001).

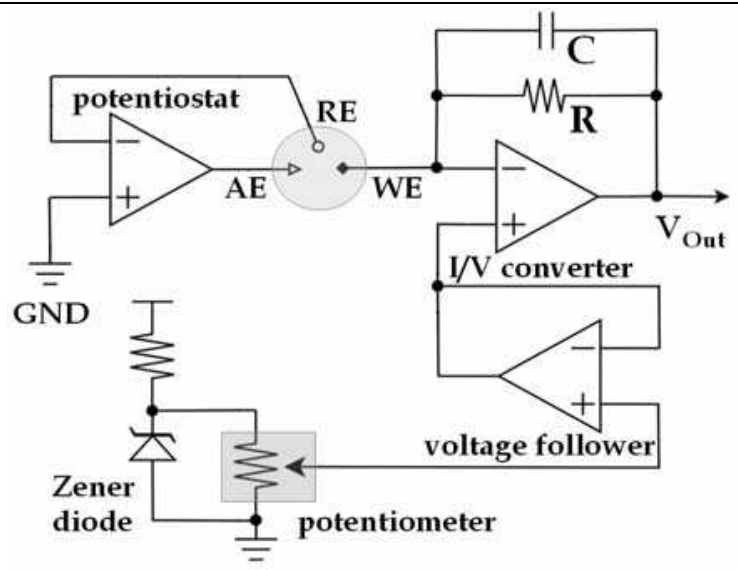

Fig. 3. Schematic of the amperometric module of the biotelemetric device working in "oxidation mode".

The current-to-voltage (I/V) converter is a single-supply adaptation of a classic transimpedance amplifier and derived form a previously-published design (Serra et al., 2007; Rocchitta et al., 2007). The transfer function of the I/ V converter is: 


$$
\mathrm{V}_{\text {Out }}=-\left(\mathrm{I}_{\text {redox }} \cdot \mathrm{R}\right)+\mathrm{V}_{\text {App }}
$$

in which $I_{\text {redox }}$ is the current flowing through the WE, $R$ is the feedback resistor and $V_{\text {App }}$ is the potential applied to the WE (versus ground). For example, working in reduction mode, a current of $0 \mathrm{nA}$ corresponds to $\mathrm{V}_{\mathrm{App}}\left(0.8 \mathrm{~V},-0.4 \mathrm{~V} v \mathcal{} \mathrm{V}_{\mathrm{z}}\right)$ while with a cathodic current of -30 $\mathrm{nA} \mathrm{V}_{\text {Out }}$ is equal to $0.5 \mathrm{~V}(\mathrm{R}=10 \mathrm{M} \Omega)$. The maximum allowable current is $\approx-80 \mathrm{nA}$ ( $\mathrm{V}_{\text {Out }}=0.0$ $\mathrm{V})$. Instead, when the system is configured in oxidation mode, a maximum anodic current of $18 \mathrm{nA}$ can be read without saturation $\left(\mathrm{V}_{\text {App }}=0.7 \mathrm{~V} ; \mathrm{V}_{\text {Out }}=2.5 \mathrm{~V} ; \mathrm{R}=100 \mathrm{M} \Omega\right)$. The feedback resistor $(\mathrm{R})$ has a capacitor in parallel $(\mathrm{C})$ to complete a low-pass filter with a cut-off frequency $\left(\mathrm{F}_{\text {cut-off }}\right)$ of $5 \mathrm{~Hz}$. The value of $\mathrm{C}$ was calculated in Farads according to the equation:

$$
\mathrm{C}=1 /\left(\mathrm{F}_{\text {cut-off }} \cdot 2 \Pi \cdot \mathrm{R}\right)
$$

A dummy cell was made based on a previously published design (Serra et al., 2007) for testing the amperometric module of the biotelemetric device before sensors calibration. The aim of the design was to devise a Thevenin current source that would reproduce the constant amperometric response of a true electrochemical cell. The voltage applied to the dummy cell was generated between the WE and RE/AE and is equal to the voltage difference between the above electrodes. The resulting currents were converted in an output voltage $\left(V_{\text {Out }}\right)$ as illustrated above. Data obtained from electronics calibration are similar to those obtained in previous studies (Bazzu et al., 2009; Calia et al., 2009).

The MSP430F2274 (Texas Instruments, TI) is the heart of the digital module. This is a 16-bit CMOS IC with ultra-low power features equipped with internal 10 bit ADCs. The microcontroller unit (MCU) performed the $A / D$ conversion of $V_{\text {Out }}, V_{\text {Batt, }}, V_{\text {App }}$ and in-chip temperature using a $2.5 \mathrm{~V}$ internal reference. After the digital signal processing (DSP) of acquired raw data, a serial data packet was generated and sent to the transceiver: the TI CC2500 multi-channel RF transceiver, designed for low-power wireless applications (2.4 $\mathrm{GHz}$.

Several pins of the microcontroller were connected to the CC2500 providing the data lines of the transceiver. In conjunction with the MCU, this component allows the realization of a serial data transmitter working at the speed of 9600 baud. A miniaturized chip antenna was integrated in the PCB board. The in-circuit-serial-programming (ICSP) bus provides the possibility of programming the MCU "on-board" in a few seconds. The digital module (Fig 1B; Fig. 1C) is commercially available pre-assembled by TI (eZ430-RF2500). A $210 \mathrm{mAh}, 3 \mathrm{~V}$ lithium coin battery (Maxell CR2032) provided the power to the biotelemetric device for up to one week in continuous transmission $(1 \mathrm{~Hz})$. A small plastic enclosure $(3.2 \times 2.1 \times 1.4 \mathrm{~mm}$; Fig. 1A) completed the implantable device (Fig. 1B, inset). The weight of the implantable device (Fig.1, inset) is 12.4 grams including battery. A second digital module (wired unit, Fig. 1C), connected to a personal computer (PC) by means of an USB-programmer, coupled the implanted biotelemetric device with the software running on the PC side (Fig. 4).

\section{Firmware and software}

The firmware to drive the MSP430F2274 MCUs was realized in C language using IAR Embedded Workbench (version 5.20, KickStart) freely available from www.ti.com. The program, which runs on the biotelemetry device, consists of two routines: the main procedure and a timer-interrupt routine called every second as illustrated in Figure 5. 


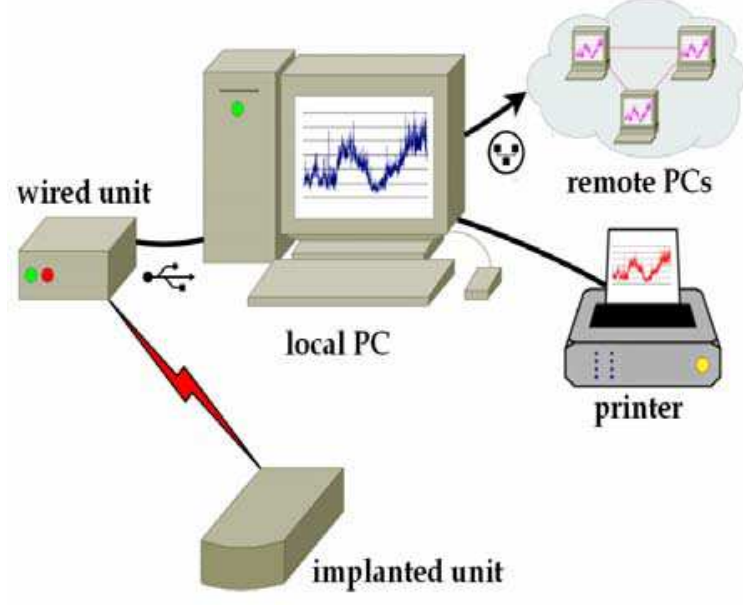

Fig. 4. Schematic of the biotelemetric system developed and used in this study.

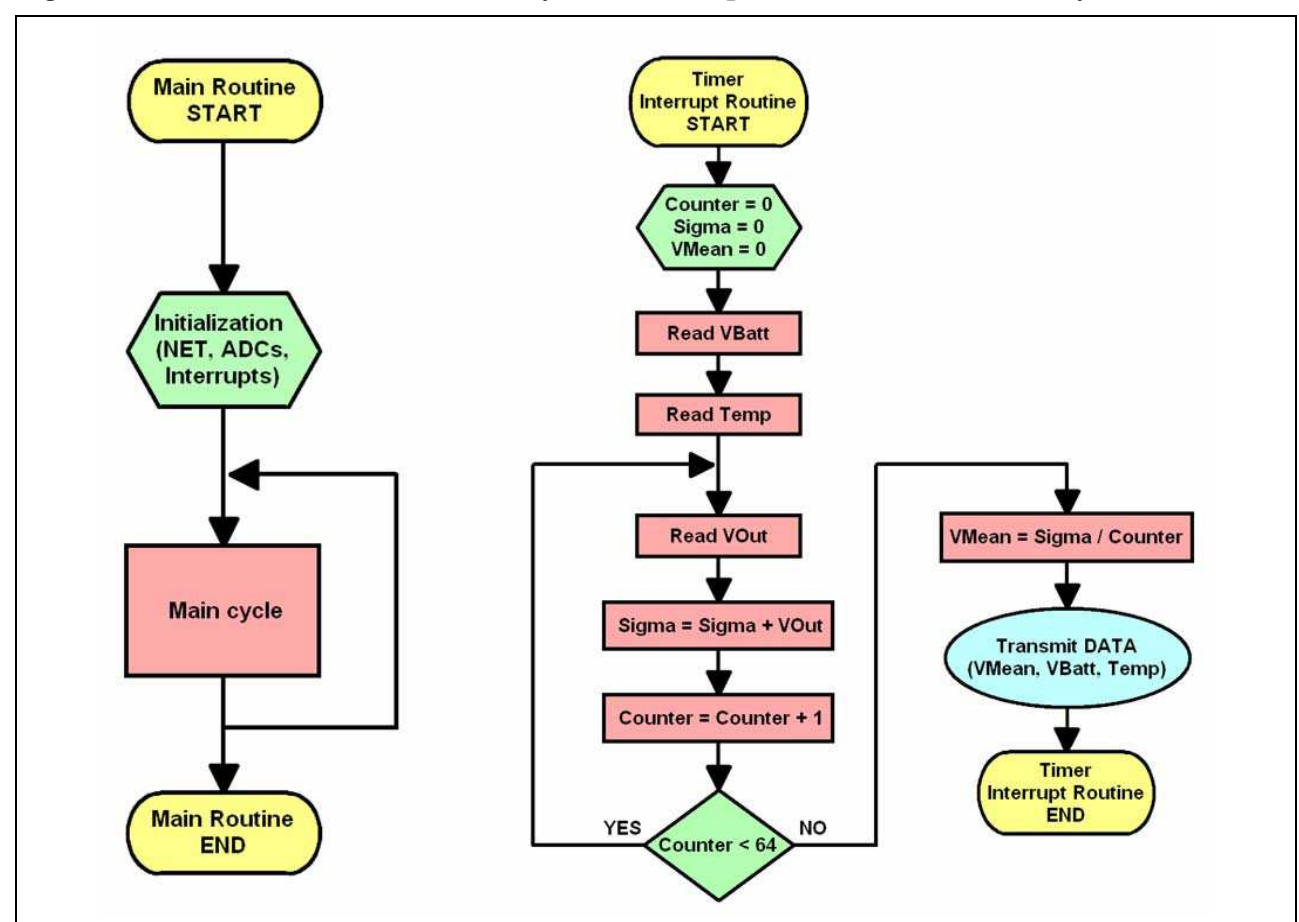

Fig. 5. Firmware running on the implantable biotelemetric device.

When the analogue signal $V_{\text {Out }}$ was digitized, the hardware ADC resolution (10 bit) was improved following the oversampling and averaging method (Pagnacco et al., 1997):

$$
\mathrm{F}_{\mathrm{os}}=4^{\mathrm{w}} \cdot \mathrm{F}_{\mathrm{s}}
$$


where $\mathrm{w}$ is the number of additional bits of resolution (2), $\mathrm{F}_{\mathrm{s}}$ is the sampling frequency (1 $\mathrm{Hz}$ ) and $\mathrm{F}_{\mathrm{os}}$ is the oversampling frequency. In accordance with the Nyquist's theorem $\mathrm{F}_{\mathrm{s}}$ was calculated as follows:

$$
\mathrm{F}_{\mathrm{s}}=2 \cdot \mathrm{F}_{\max }
$$

in which $\mathrm{F}_{\max }$ has been fixed to $2 \mathrm{~Hz}$. To do that, the MCU acquired and accumulated 64 consecutive samples then divided the result by $2^{6}$ (Fig. 5). This technique increased the ADC resolution from 10 to 12 bits. The RF data packets ( 1 per second), sent by the MCU, were encapsulated in an Open Source Stack (SimpliciTI ${ }^{\mathrm{TM}}$ ), implemented by Texas Instruments for the development of low power wireless NETs. Up to 100 implantable units, with an 8 bit ID memorized in their E2PROM, can share the same transmission channel. The interruptdriven routine on the receiver unit, mounting a second MSP430F2274, communicates to the PC using USB and filters the IN-OUT data. The firmware was downloaded to the MCUs using the TI USB programmer connected to the ICSP bus (Fig. 6).

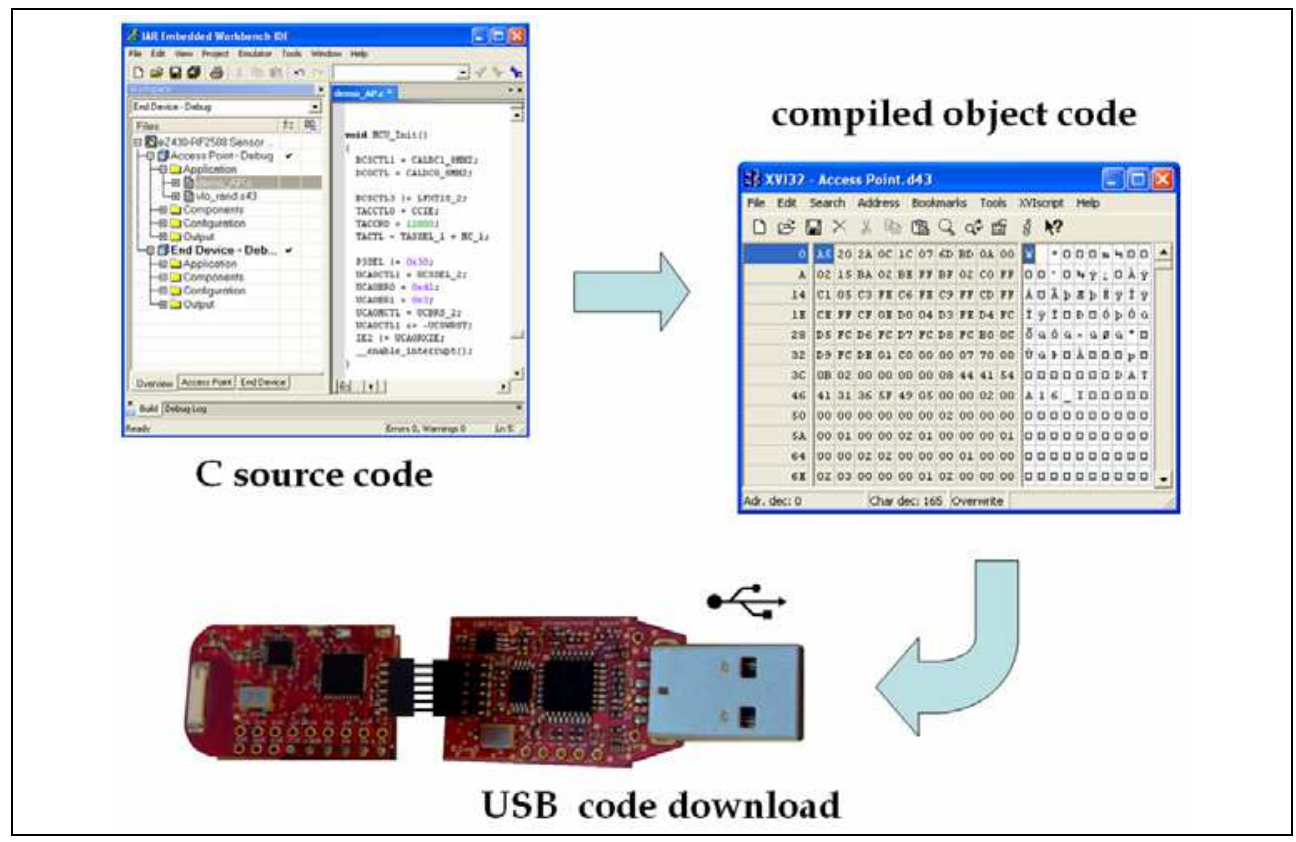

Fig. 6. Program process of MSP430F2274 consisting on edit-compile-download cycle.

The software, running on the PC under Windows XP Professional ${ }^{\mathrm{TM}}$ or Vista $^{\mathrm{TM}}$, communicates thought the USB by using the low-level driver freely available from www.ti.com. The graphic user interface (Fig. 7) was developed using Profilab Expert ${ }^{\circledR}$ (version 4.0 from Abacom) while the dynamic link library (DLL) serial-data-parser was programmed in C (Dev-C++ ver. 4.9.9.2).

The application (capable of plotting, storing and retrieving data) interfaces the system with a printer via USB and a Local Area Network (LAN) and Internet via TCP/IP (Fig. 4). A software alarm was generated if $\mathrm{V}_{\text {Batt }}<2.7 \mathrm{~V}$, signal strength (RSSI) too low or a data reception time-out occurred. 


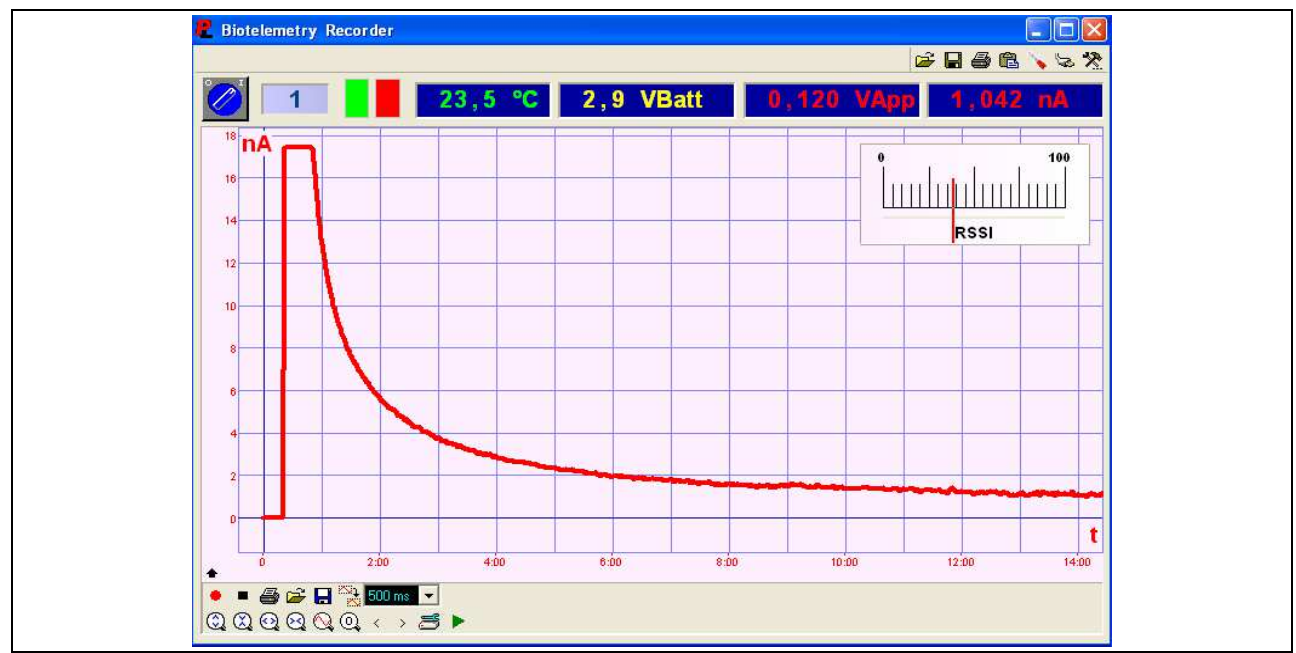

Fig. 7. Simple graphic user interface of the data-acquisition software running on the PC.

\section{Statistical analysis}

Concentrations of $\mathrm{O}_{2}$ were expressed in $\mu \mathrm{M}$ while AA, glucose and lactate in mM. Oxygen, ascorbate and $\mathrm{H}_{2} \mathrm{O}_{2}$ signals were expressed in $\mathrm{nA}$ and given as baseline-subtracted data $(\triangle \mathrm{nA})$. The sensors in-vitro response was characterized immediately before implantation and the electrochemical parameters evaluated before in-vivo experiments. The changes of brain tissue neurochemicals were calculated as absolute variations versus the corresponding baselines and their striatal concentrations were estimated using pre-implantation in-vitro calibrations.

Statistical significance of changes was evaluated using paired $t$-tests between the means of 300 consecutive recordings before (baseline) and during the maximum magnitude of neurochemical changes as a result of physiological stimulation (tail pinch).

Pearson's correlation coefficient was used to show correlation significance of current variations induced by tail pinches among $\mathrm{O}_{2}, \mathrm{AA}$, glucose and lactate. Immediately after the stimulus application, the first five minutes of raw data $(n=300)$ were compared point-bypoint. The null hypothesis was rejected when $\mathrm{p}<0.05$.

\section{Design, construction and calibration of oxygen and ascorbic acid microsensors}

Oxygen microsensor construction and calibration were performed as previously described (Bazzu et al., 2009; Calia et al., 2009). Briefly, $1 \mathrm{~mm}$ silver wire $(25 \mathrm{~mm}$ in length; $\varnothing=125 \mu \mathrm{m}$, Advent Research Materials, Suffolk, UK) was introduced in a silica capillary tube (10 $\mathrm{mm}$ in length; I.D. $\varnothing=180 \mu \mathrm{m}$, Polymicro Technologies, Phoenix, USA), partially filled with epoxycarbon (EC) obtained mixing $450 \mathrm{mg}$ of graphite with $350 \mathrm{mg}$ epoxy resin (Araldite-M®, Sigma-Aldrich, Milan, Italy). A $180 \mu$ m diameter carbon composite disc electrode was made up and left 12 hours at $60^{\circ} \mathrm{C}$. A conical shape was provided to the microsensor by drilling the tip. 
The final oxygen microsensors (Fig. 8) had a length about $250 \mu \mathrm{m}$, a surface of $0.00145 \mathrm{~cm}^{2}$ and a tip $<25 \mu \mathrm{m}$. Nitrocellulose (NC, collodion) treatment was carried out dipping the microsensor in the collodion solution (4\% nitrocellulose in ethanol/diethyl ether) 3 times and drying it for 1 hour at $40{ }^{\circ} \mathrm{C}$ after each coating. Cellulose nitrate membrane, because of its hydrophobic properties, sets a barrier for large organic molecules, as proteins, avoiding poisoning of microsensor surface while can be crossed by small charged ions and gases (Bazzu et al., 2009).

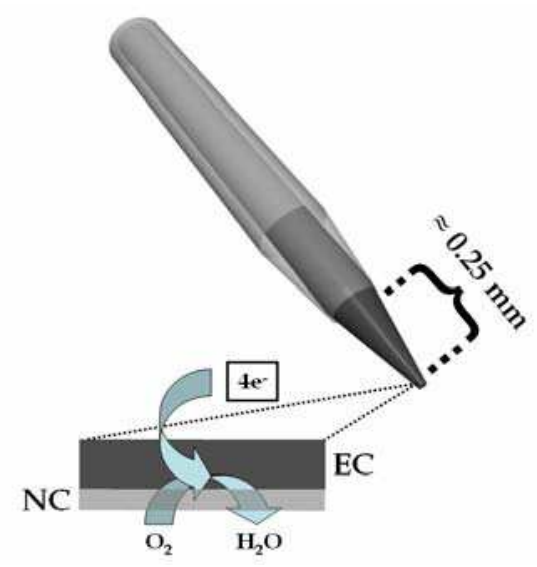

Fig. 8. Schematic representation of the oxygen microsensor used in this study.

$\mathrm{O}_{2}$ reduction potential was experimentally determined in a previous study (Bazzu et al., 2009) using cyclic voltammetry and fixed at at $-400 \mathrm{mV}$ vs $\mathrm{Ag} / \mathrm{AgCl}$ reference electrode. Constant potential amperometry (CPA) was used for in-vitro and in-vivo calibrations and experiments. No significant interferences were remarked on exposing sensors to other electroactive molecules (AA, UA, DA, DOPAC and HVA) present in the striatal extracellular fluid at pharmacologically significant concentrations (Calia et al., 2009). $\mathrm{O}_{2}$ microsensor was calibrated by adding known volumes of a standard $\mathrm{O}_{2}$ solution $(100 \%)$ to nitrogenated PBS and only sensors with sensitivity lower than $10 \mu \mathrm{M}$ were chosen. All in-vitro calibrations of oxygen microsensors were carried out $24 \mathrm{~h}$ after manufacture, immediately before implantation, using a previously-described electrochemical cell (Serra et al., 2007; Rocchitta et al., 2007) appropriately set for oxygen (Bazzu et al., 2009). The calibration (Fig. 9) exhibited good linearity showing a slope of $-254 \pm 32 \mathrm{pA} \mu \mathrm{M}^{-1}$ of $\mathrm{O}_{2}\left(\mathrm{R}^{2}=0.999 ; n=6\right)$, in line with previous observations (Calia et al., 2009).

AA microsensors (Fig. 10) were manufactured in the same way as oxygen microsensors without the collodion layer or any further surface modification.

In-vitro calibrations of ascorbic acid microsensors were carried out in fresh PBS at room temperature $\left(25^{\circ} \mathrm{C}\right)$ before implantation. A constant potential of $+120 \mathrm{mV}$ was applied and after a stabile baseline was reached, known amount of ascorbic acid stock solution were added to PBS in order to obtain concentrations ranging from 0 to $5 \mathrm{mM}$.

AA microsensors, calibrated before implantation (Fig. 11), showed good sensitivity and good linearity $\left(2.96 \mathrm{nA} \pm 0.1 \mathrm{mM}^{-1}, \mathrm{R}^{2}=0.998, \mathrm{n}=6\right)$. 


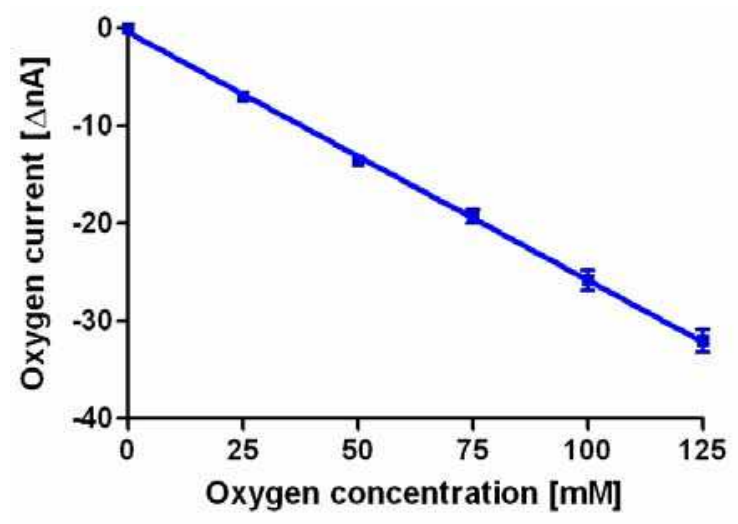

Fig. 9. Oxygen microsensor in-vitro calibration.

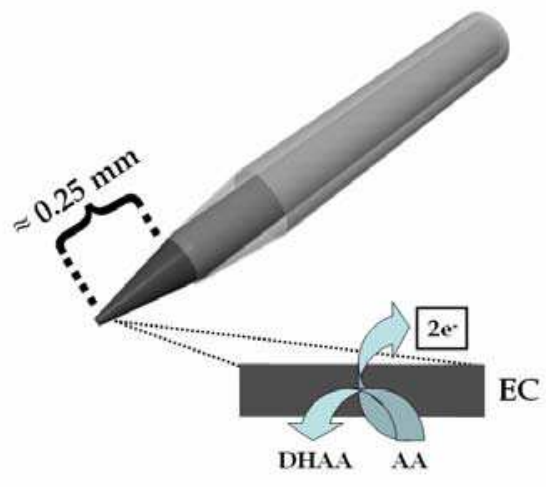

Fig. 10. Schematic representation of the ascorbic acid microsensor used in this study.

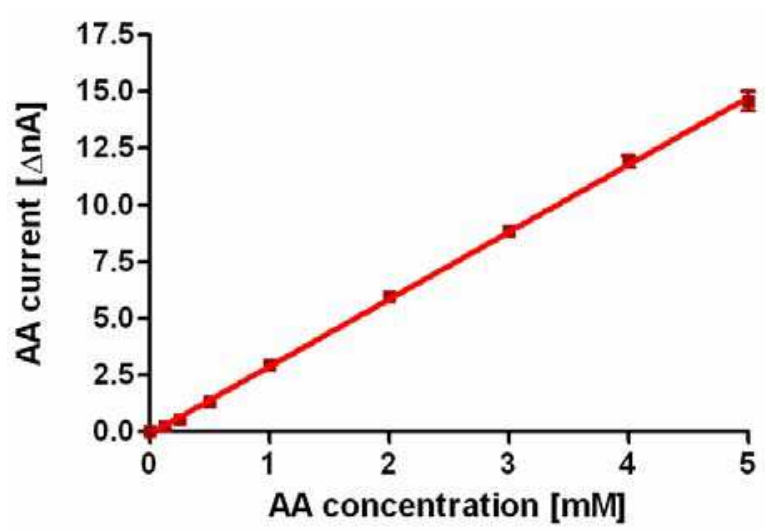

Fig. 11. Ascorbic acid microsensor in-vitro calibration. 


\section{Design, construction and calibration of glucose and lactate biosensors}

The design of the glucose biosensors (Fig. 12) has been previously described in detail (Serra et al., 2007). Briefly, $1 \mathrm{~mm}$ platinum (Pt) cylinder, obtained cutting Teflon-insulated Pt wire ( $\varnothing=125 \mu \mathrm{m}$, Advent Research Materials, Suffolk, UK), was immersed for $5 \mathrm{~min}$ into a solution of glucose oxidase (GOx) to allow adsorption. After $10 \mathrm{~min}$ drying at room temperature, the biosensor was placed in the cell filled with $5 \mathrm{ml}$ of nitrogenated PBS containing the o-phenylenediamine monomer (OPD, $250 \mathrm{mM}$ ). The electrosynthesis of polyo-phenylenediamine (p-OPD) was carried out at $+700 \mathrm{mV}$ vs $\mathrm{Ag} / \mathrm{AgCl}$ reference electrode for $15 \mathrm{~min}$. After electropolymerization, the biosensor was stored in fridge $\left(4^{\circ} \mathrm{C}\right)$.

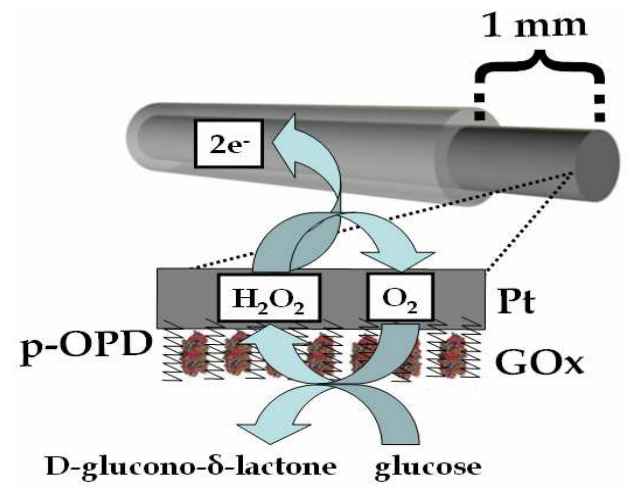

Fig. 12. Schematic representation of the glucose biosensor used in this study.

The in-vitro calibration of glucose biosensor was made in air-bubbled PBS performing ten successive injections of glucose $(0.2,0.4,0.6,1,2,10,20,60,100,140 \mathrm{mM})$. The calibration data (Fig. 13) well fitted with the Michaelis-Menten equation $\left(R^{2}=0.984, n=6\right)$ with a $V_{M A X}$ of $59.6 \pm 0.8 \mathrm{nA}$ and $\mathrm{K} \mathrm{K}_{\mathrm{M}}$ of $5.6 \pm 0.4 \mathrm{mM}$. The response to low concentration of glucose $(0-2 \mathrm{mM}$; Fig. 13, inset), revealed excellent linearity $\left(R^{2}=0.999, n=6\right)$ and a slope of $8.9 \pm 0.08 \mathrm{nA} \mathrm{mM}^{-1}$.

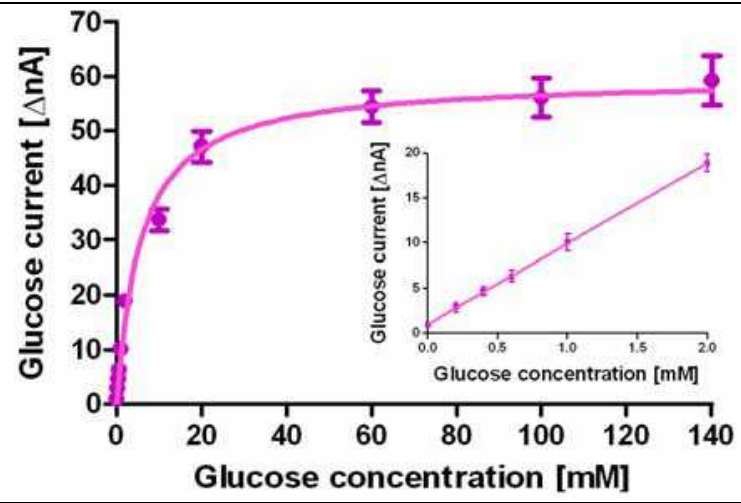

Fig. 13. In-vitro calibration of glucose biosensor (see text).

The fabrication of the lactate biosensors (Fig.14) has been derived from a previously described procedure used to make glutamate biosensors (McMahon et al., 2006). A Pt 
cylinder $(1 \mathrm{~mm})$ was placed in the electrochemical cell containing nitrogenated PBS and OPD monomer and p-OPD was electrosynthesized as previously described for glucose biosensor. The $\mathrm{Pt} / \mathrm{p}-\mathrm{OPD}$ cylinder was immersed (quick dip) into a solution of polyethylenimmine (PEI, 0.5\%in water)-LOx (25 U/50 $\mu \mathrm{l}$ of PBS) to allow oxydase adsorption. After 5 min drying at room temperature, the dipping procedure was repeated four times.

With the purpose of increasing the $\mathrm{K}_{\mathrm{M}}$ of the biosensor, a diffusion-reducing membrane (Schuvailo et al., 2006) was applied on top of the PEI-LOx layers by dipping the biosensor in a polyurethane (PU) solution (2.5\% in tetrahydrofurane). Finally, the biosensor was stored in fridge.

Constant potential amperometry (CPA) was used for in-vitro and in-vivo experiments fixing the $\mathrm{H}_{2} \mathrm{O}_{2}$ oxidation potential at $+700 \mathrm{mV}$ (Serra et al., 2007) vs Ag/AgCl.. All in-vitro calibrations were performed in fresh PBS $24 \mathrm{~h}$ from sensors' manufacture as previously described in detail (Rocchitta et al., 2007).

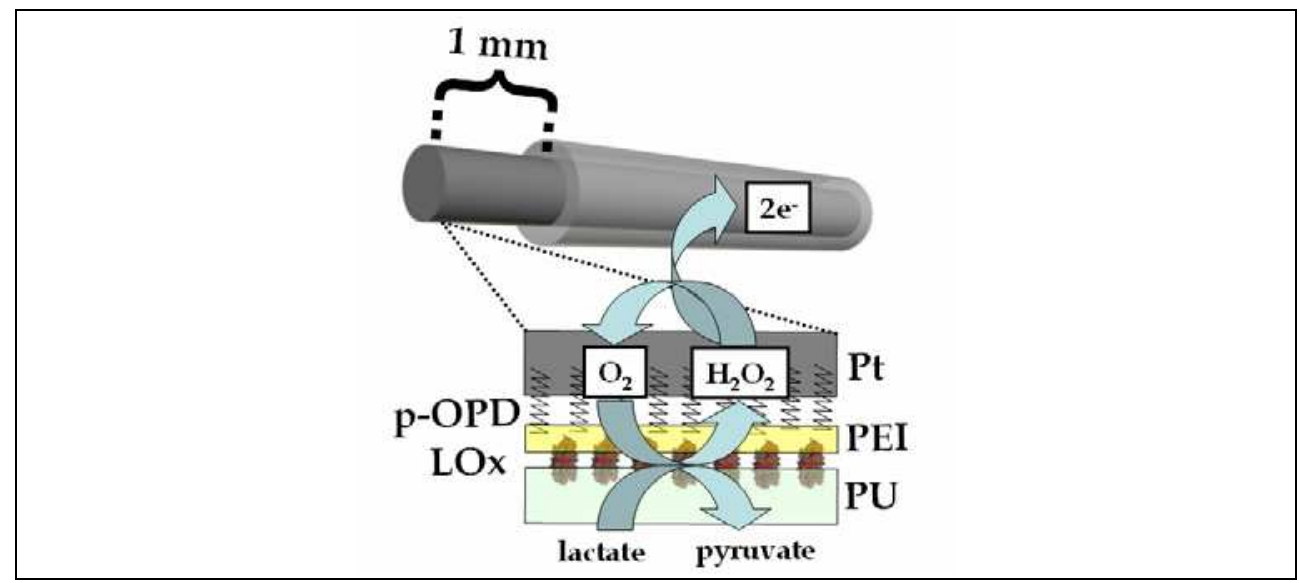

Fig. 14. Schematic representation of the lactate biosensor used in this study.

The in-vitro response of lactate biosensor was determined only before implantation adding known amounts of lactate in the electrochemical cell giving concentrations ranging between 0 and $150 \mathrm{mM}$.

Calibrations showed a classical Michaelis-Menten kinetic $\left(R^{2}=0.944, n=6\right)$ with $V_{M A x}$ and $K_{M}$ equal respectively to $92.8 \pm 2 \mathrm{nA}$ and $8.7 \pm 0.9 \mathrm{mM}$ (Fig. 15). Linear region was evaluated at low concentration (0-5 mM) and it showed good linearity $\left(\mathrm{R}^{2}=0.997, \mathrm{n}=6\right)$ with a slope of $6.7 \pm 0.2 \mathrm{nA} \mathrm{mM}^{-1}$ (Fig. 15, inset).

No significant interference signals were observed on exposing biosensors to AA or other electroactive molecules present in the striatal extracellular fluid, even at pharmacologically relevant concentrations (Calia et al., 2009).

\section{Animals and neurosurgery}

Male Wistar rats (Morini R. Emilia, Italy), weighing 250-350 g were used in all experiments. Rats were kept under standard animal care conditions with $12 \mathrm{~h}$ light/dark cycle, and room temperature $21^{\circ} \mathrm{C}$, food and water ad libitum. 


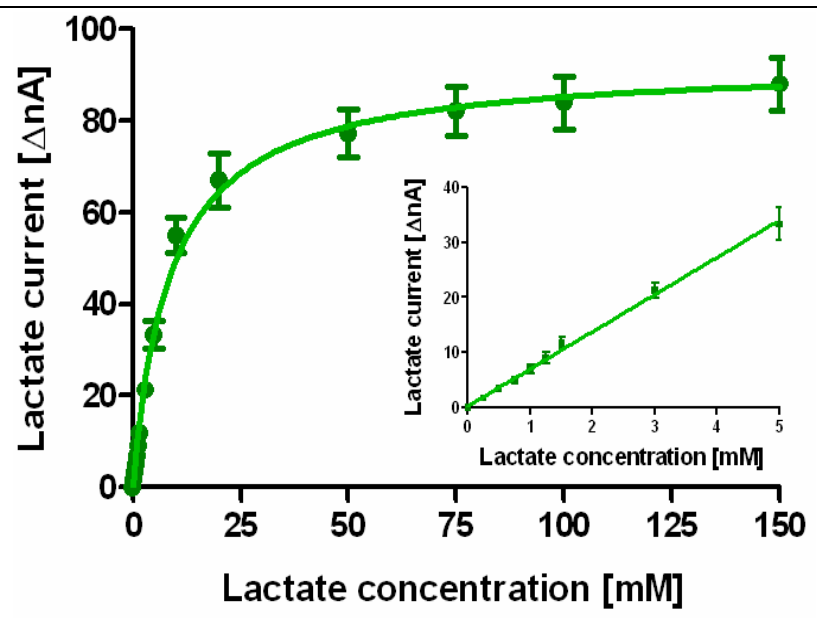

Fig. 15. In-vitro calibration of lactate biosensor (see text).

All procedures were licensed under the European Community directive 86/609 included in Decreto No. 116/1992 of the Italian Ministry of Public Health.

Stereotaxic surgery was performed under chloral hydrate ( $400 \mathrm{mg} \mathrm{Kg}^{-1}$ i.p.) anesthesia and body temperature during anaesthesia was maintained at $37^{\circ} \mathrm{C}$ by means of an isothermal heating pad.

Before each experiment, the health of the animals was assessed according to published guidelines (Wolfensohn and Lloyd, 2003).

$\mathrm{O}_{2}$ and AA microsensors, glucose and lactate biosensors were implanted in the right striatum (Fig. 16) using the following coordinates from the atlas of Paxinos \& Watson (Paxinos \& Watson, 2007): A/P +0.5 from bregma, $+2.5 \mathrm{M} / \mathrm{L}$, and $-4.0 \mathrm{D} / \mathrm{V}$ from dura. Reference and Auxiliary electrodes were implanted in the parietal cortex.

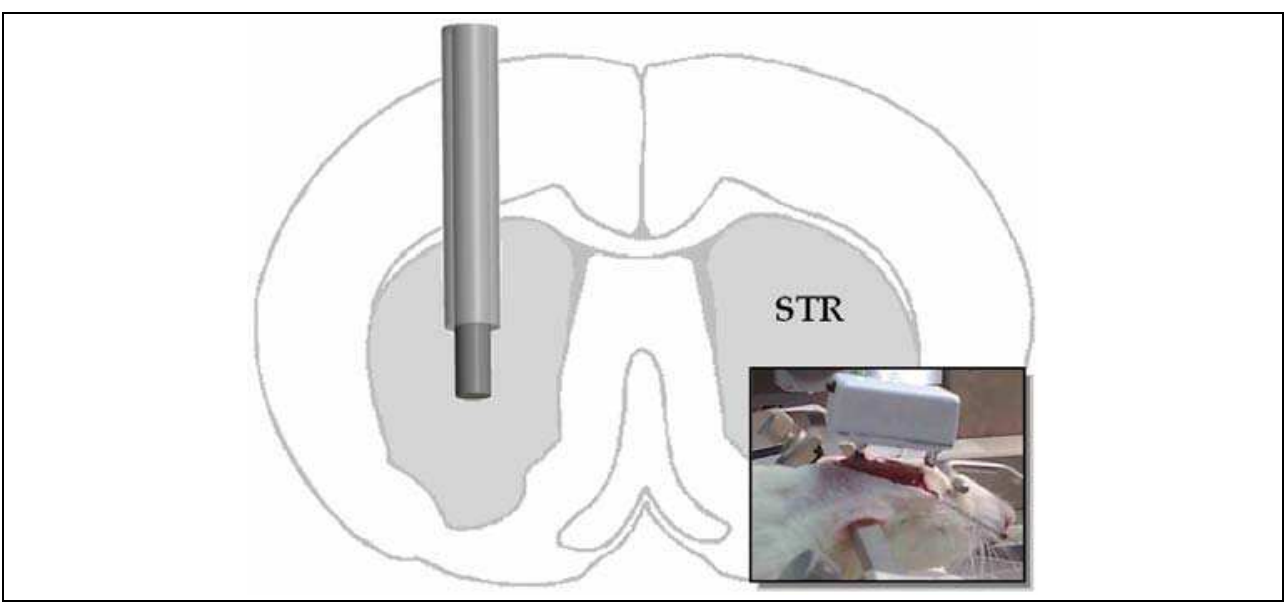

Fig. 16. Amperometric sensor inserted in the right striatum by means of sterotaxic surgery. The sensor was wired to the biotelemetric device fixed to the skull (inset). 
The biotelemetric device was fixed by mean of two screws inserted in the skull (Fig. 16, inset), as previously described (Bazzu et al., 2009; Calia et al., 2009).

Following surgery, the animals were housed in large Plexiglas bowls (45 cm diameter), and maintained in a temperature- and light- controlled environment, with free access to food and water. The sensors were connected $24 \mathrm{~h}$ after surgery. The monitoring of neurochemicals started with the animal in its home bowl allowing the rat free movement (Fig. 17).

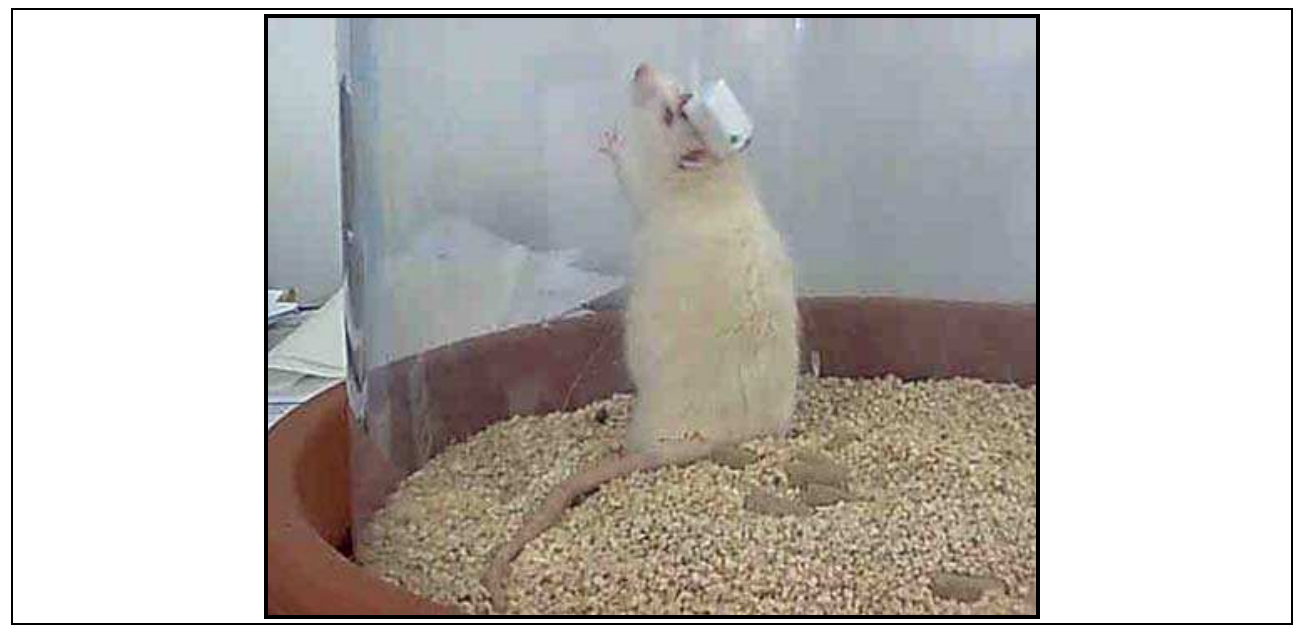

Fig. 17. Biotelemetric device implanted in a freely-moving rat.

\section{In-vivo experiments and results}

Baseline recordings and physiological stimulation were carried out within the first day after stereotaxic surgery, starting $24 \mathrm{~h}$ after implantation. The Oxygen microsensor reached a stable baseline $(-24.3 \pm 2.7 \mathrm{nA})$ after a period of about 50 minutes from the application of the working potential. Considering that the background current of the microsensor in nitrogensaturated PBS was $-14.2 \pm 0.9 \mathrm{nA}$, it is possible to estimate the concentration of $\mathrm{O}_{2}$ using invitro pre-calibration; this was found to correspond to $39.8 \pm 7.1 \mu \mathrm{M}$, a value in agreement with previous results (Bazzu et al., 2009; Calia et al., 2009). Physiological stimulation as fiveminute tail pinch (Fig. 18), administered in order to increase neural activity and to promote regional cerebral blood flow ( $\mathrm{rCBF}$ ), led to an increased motor activity yielding to a striatal $\mathrm{O}_{2}$ current of $-2.97 \mathrm{nA}$, corresponding to $+11.69 \mu \mathrm{M}$, statistically different from baseline ( $\mathrm{p}<0.001$; Fig. 18, inset).

Striatal oxygen dynamics, following physiological stimulation, resulted in a rise in the local $\mathrm{O}_{2}$ signal, mainly related to an increase of $\mathrm{rCBF}$ during neural activation in agreement with previous findings (Bazzu et al., 2009; Calia et al., 2009).

A stable AA baseline was reached after a period of about 25 minutes. The calculated AA baseline corresponded to a concentration of $566 \mu \mathrm{M}$, in line with previous findings (Calia et al., 2009). A physiological increase ( $\mathrm{p}<0.001$; Fig. 19, inset) of striatal AA current $(+0.447 \mathrm{nA}$ corresponding to $+228 \mu \mathrm{M}$ ) was observed immediately after the administration of a $5 \mathrm{~min}$ tail pinch (Fig. 19). 


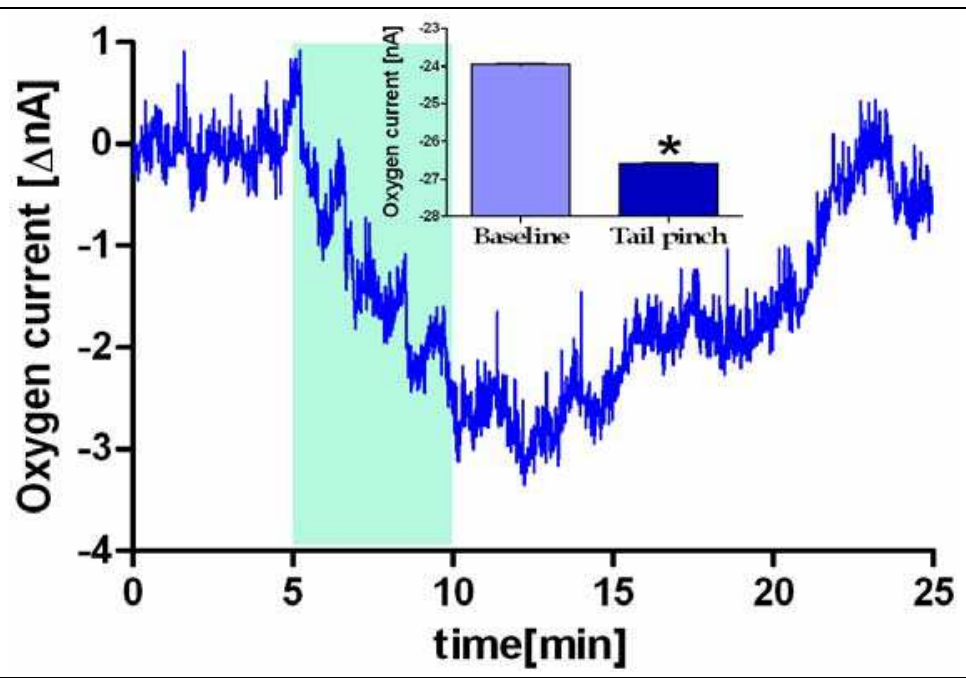

Fig. 18. Effect of physiological stimulation (5 min. tail pinch, vertical band) on striatal dissolved oxygen.

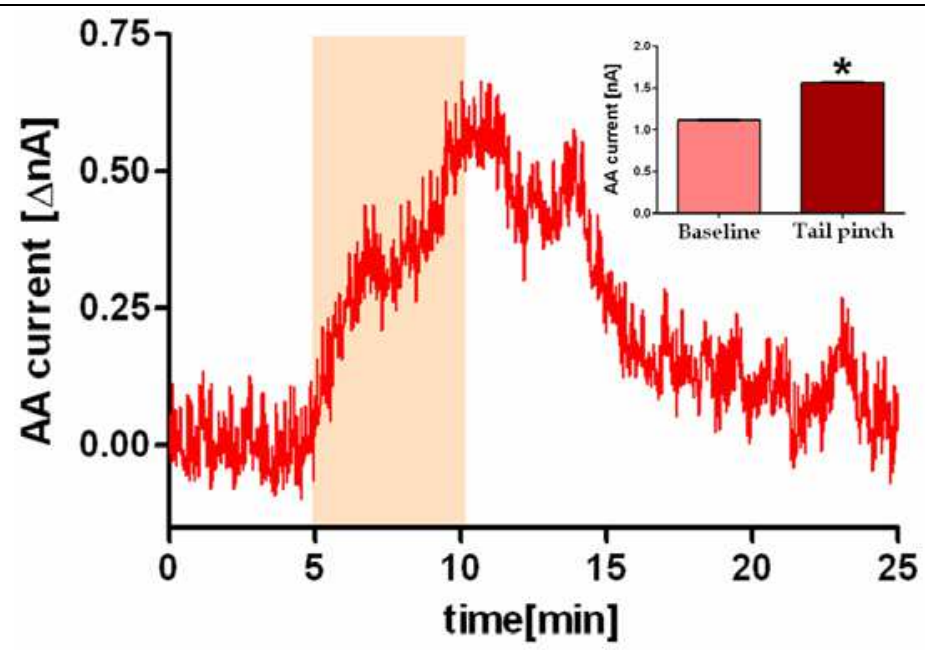

Fig. 19. Effect of a $5 \mathrm{~min}$. tail pinch (vertical band) on striatal AA.

This result is consistent with the activation of the AA/glutamate heteroexchange system (Rice, 2000) in which AA release is related to glutamate release and uptake subsequent to neural activation (Miele et al., 2000).

Glucose biosensor in-vivo experiments were carried out using the same procedures as oxygen and AA ones. Thirty minutes after biosensor activation a stable anodic current corresponding to $4.6 \pm 0.24 \mathrm{nA}(517 \pm 26 \mu \mathrm{M}$ from in-vitro calibration) was reached. Physiological stimulation (Fig. 20) produced a significant decrease of glucose signal (-167 $\mu \mathrm{M}$; Fig. 20, inset) followed by its increase after stimulus suspension. 


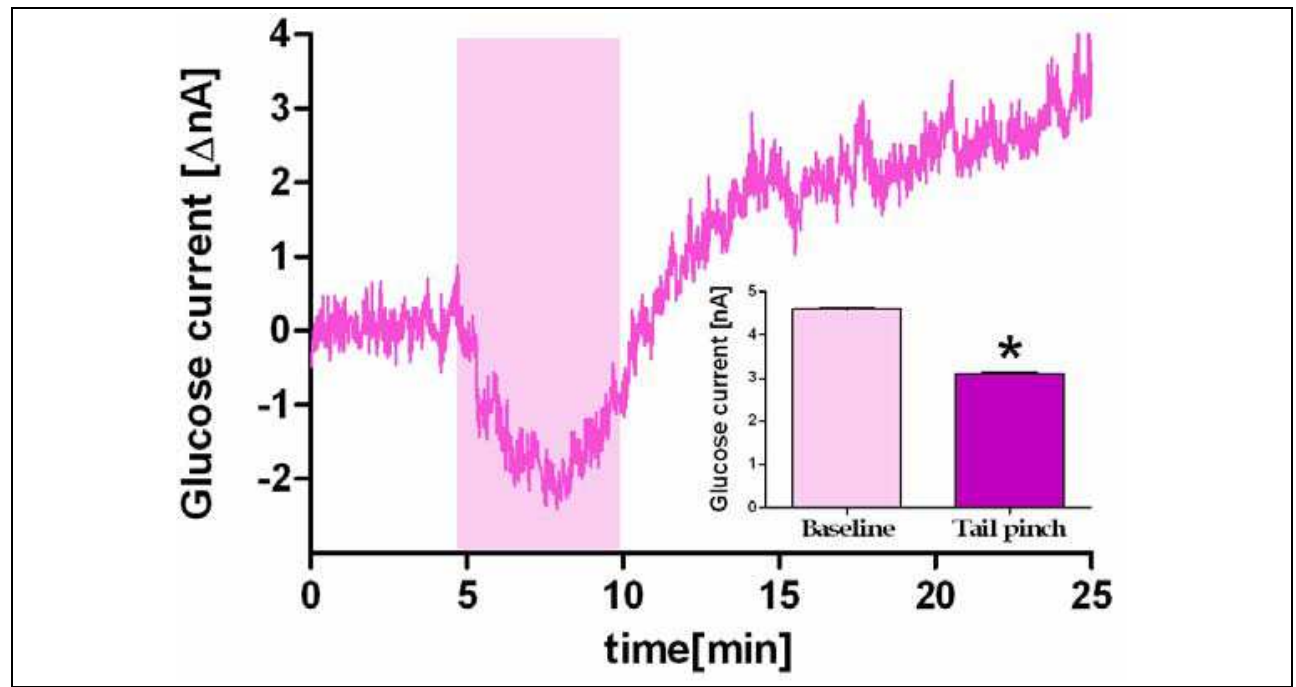

Fig. 20. Effect of a $5 \mathrm{~min}$. tail pinch (vertical band) on striatal glucose.

A stable baseline was observed $40 \mathrm{~min}$ after lactate biosensor polarization and corresponded to $5.09 \pm 0.43 \mathrm{nA}(759 \pm 62 \mu \mathrm{M}$ from the above in-vitro calibration). A five-minute tail pinch (Fig. 21) resulted in a significant increase of lactate signal during stimulus administration and after stimulus suspension $(+544 \mu \mathrm{M}, \mathrm{p}<0.001$; Fig. 21, inset).

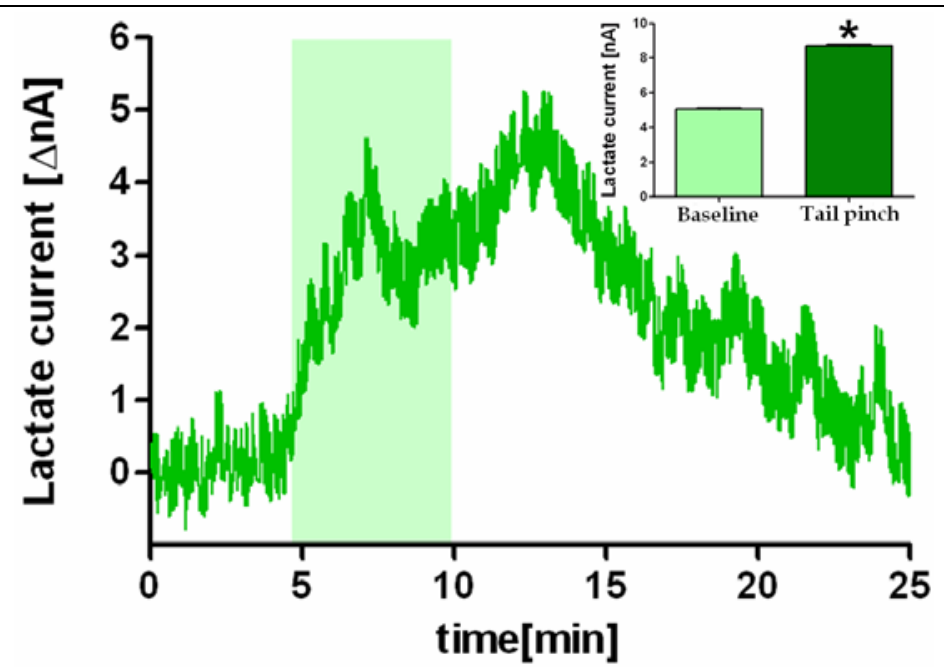

Fig. 21. Effect of a $5 \mathrm{~min}$. tail pinch (vertical band) on striatal lactate.

These results are suggestive of glucose consumption and lactate production during neural activation followed by an increase of extracellular levels of glucose subsequent to astroglial glycogenolysis (Fillenz et al., 1999). Figure 22 shows Pearson's correlation analysis of current variations induced by tail pinches among $\mathrm{O}_{2}$, AA, glucose and lactate. 


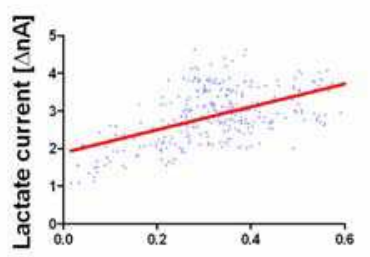

AA current $[\triangle \mathrm{nA}]$

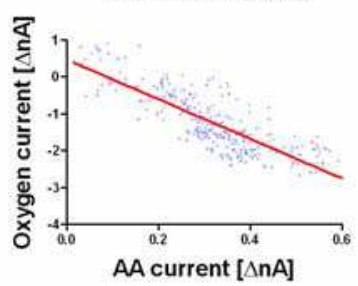

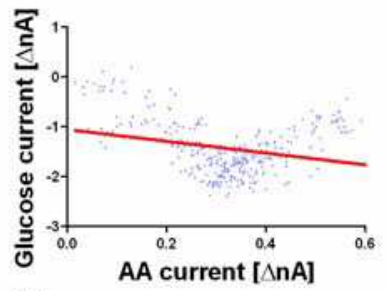

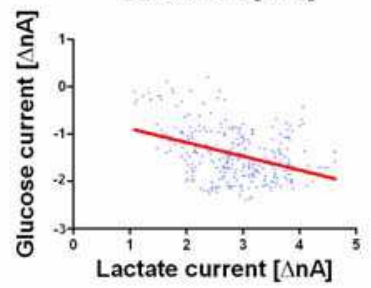

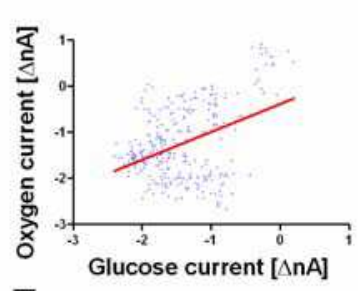

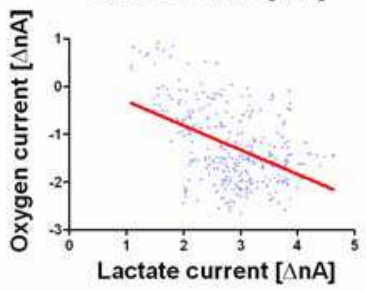

Fig. 22. Pearson's correlation analysis of striatal neurochemical changes during neural activation.

It is important to remember that an increase in anodic currents (AA, glucose and lactate) reflects a striatal increase of the above neurochemicals while an increase in extracellular dissolved $\mathrm{O}_{2}$ levels, corresponds to an increase in cathodic oxygen current, resulting in a more negative signal. Results of correlation analysis are summarized in Table 1.

\begin{tabular}{|l|l|l|l|}
\hline & Ascorbic Acid & Glucose & Lactate \\
\hline Oxygen & $\mathbf{r}=-\mathbf{0 . 8 1 9}$ & $\mathbf{r}=\mathbf{0 . 4 0 1}$ & $\mathbf{r}=-0.457$ \\
& $\mathrm{P}<0.0001$ & $\mathrm{P}<0.0001$ & $\mathrm{P}<0.0001$ \\
\hline Ascorbic Acid & & $\mathbf{r}=-\mathbf{0 . 2 6 6}$ & $\mathbf{r}=\mathbf{0 . 5 1 8}$ \\
& & $\mathrm{P}<0.0001$ & $\mathrm{P}<0.0001$ \\
\hline Glucose & & & $\mathbf{r}=-0.388$ \\
& & & $\mathrm{P}<0.0001$ \\
\hline
\end{tabular}

Table 1. Results of correlation analysys of striatal neurochemical changes during neural activation.

After each experiment, rats were sacrificed with an injection of chloral hydrate $(800 \mathrm{mg} \mathrm{Kg}-1$ i.p.). The location of each sensor was established by post-mortem histology. Brains were fixed in formal saline and $50 \mu \mathrm{m}$ coronal sections were made with a cryostat. The slices were stained with cresyl violet and examined under a microscope.

\section{Discussion and conclusion}

In this chapter we have described the development of a distributed sensor NET for biotelemetric monitoring of brain neurochemistry using amperometric microsensors and biosensors. The implantable biotelemetric units, based on simple and inexpensive components, have been successfully used for accurate transduction of the electrochemical signals generated on the surface of the sensors implanted in the striatum of freely-moving rats. At this stage of development the system exhibits high stability and excellent linear response in the nanoampere current range. The choice of low-power CMOS technology makes the project suitable of further improvements such as the reduction of the power 
consumption. The use of surface mount components and careful PCB design will make it possible to further miniaturize the circuitry. As result of in-vivo experiments, we have shown some preliminary data obtained monitoring important brain molecules during shorttime neural activation ( $5^{\prime}$ tail pinch). The study was carried out using new microsensors, biosensors and the newly-developed biotelemetric device in order to record real-time changes of key neurochemical markers of brain bioenergetic metabolism. Indeed, all studied species (oxygen, AA, glucose and lactate) are implicated in brain energetics.

Recently, Castro and coworkers (Castro et al., 2009) proposed a new pivotal role for AA as modulator in the metabolic switch between glucose and lactate as energetic substrate of neurons. This review paper, mainly based on in-vitro results, summarizes the evidences of the relationships among glutamate, AA, glucose and lactate during neural activation. In figure 23, we repropose the model suggested by Castro, updated on the basis of our in-vivo results. In brief, in normal conditions both neurons and astrocytes use glucose as energetic substrate. After neural activation, cortico-striatal endings release glutamate (1) in the striatal extracellular compartment (Miele et al., 2000). Immediately after, GLU is taken by astrocytes from the synaptic cleft and exchanged (Rice, 2000) with AA (2). The in-vivo increase of extracellular AA during tail pinch is in accord with this mechanism. The glutamate entry into astrocyte stimulates glucose internalization (3), glycolysis (4) and lactate efflux (5). We observed a reduction of extracellular glucose and an increase of lactate during tail pinch in agreement with this model. Finally, ascorbic acid enters neurons (6) through a specific transporter (SVCT2) and activates the metabolic switch (Castro et al., 2009), stimulating lactate uptake in neurons (7) and inhibiting glucose consumption (8). The rise in the local $\mathrm{O}_{2}$ signal,

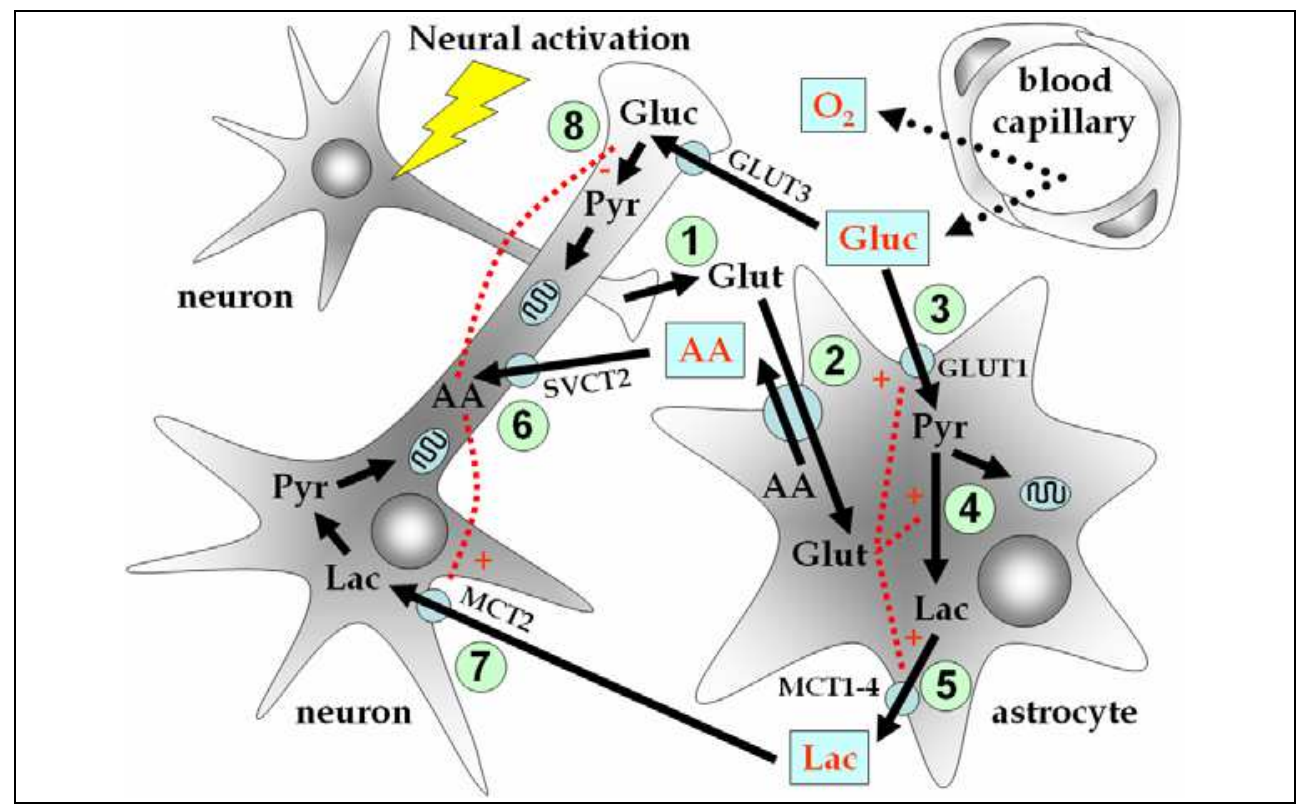

Fig. 23. Neurochemical pathway involved in brain energetic metabolism during neural activation. Glut: glutamate; Gluc: glucose; Lac: lactate; Pyr: pyruvate; GLUT: glucose transporter; SVCT: AA transporter; MCT: lactate transporter. 
during neural activation, might reflect an increase of rCBF (Bazzu et al., 2009; Calia et al., 2009). Immediately after the end of the physiological stimulation, AA current inverted its trend and slowly $(10 \mathrm{~min})$ returned to baseline levels. Oxygen and lactate currents continued to rise for $5 \mathrm{~min}$ after the end of the tail pinch then slowly decreased to baseline levels. The drop of glucose during neural activation was followed by its increase as result of astroglial glycogenolysis (Fillenz et al., 1999). Post-activation data are complex to interpret and suggest the return to normal (inactive) condition with glucose as energetic substrate for neurons. It is important to remember that AA is oxidized to DHAA by ROS and RNS in neurons (Serra et al., 2002). DHAA, secreted in the extracellular space, enters astrocyte through GLUT1 transporter and is back-reduced to AA (Hediger, 2002). A sustained increase of extracellular glucose could interfere with AA/DHAA cycle resulting in oxidative stress, AA loss and neuron damage.

These in-vivo results indicate that, during neural activation in physiological conditions, extracellular striatal changes of the above neurochemicals mainly reflect astrocyte response to glutamatergic stimulation. Further in-vivo pharmacological studies are necessary to confirm in-vitro evidences on bioenergetic substrates used by neurons in different experimental conditions.

\section{Acknowledgment}

The authors acknowledge the Italian distributors of Texas Instruments for free samples of integrated circuits. The research was supported by the Ministero dell'Istruzione, dell'Universita`e della Ricerca (MIUR, PRIN 2007 fund), University of Sassari (ex 60\% fund) and Fondazione Banco di Sardegna.

This work is dedicated to the beloved memory of Giovanna Pisanu who left us too early.

\section{References}

Andersen, J.K. (2004) Oxidative stress in neurodegeneration: cause or consequence? Nat. Med., 10, 18-25.

Aubert, A.; Costalat, R.; Magistretti, P.J.; Pellerin, L. (2005) Brain lactate kinetics: modeling evidence for neuronal lactate uptake upon activation. Proc. Natl. Acad. Sci., 102, 16448-16453.

Bazzu, G.; Puggioni, G.G.; Dedola, S.; Calia, G.; Rocchitta, G.; Migheli, R.; Desole, M.S.; Lowry, J.P.; O'Neill, R.D.; Serra, P.A. (2009). Real-time monitoring of brain tissue oxygen using a miniaturized biotelemetric device implanted in freely-moving rats. Anal. Chem., 81, 2235-2241.

Calia, G.; Rocchitta, G.; Migheli, R.; Puggioni, G.G.; Spissu, Y.; Bazzu, G.; Mazzarello, V.; Lowry, J.P.; O'Neill, R.D.; Desole, M.S. \& Serra, P.A. (2009) Biotelemetric Monitoring of Brain Neurochemistry in Conscious Rats Using Microsensors and Biosensors. Sensors, 9, 2511-2523.

Castro, M.A.; Beltrán, F.A.; Brauchi, S.; Concha, II. (2009) A metabolic switch in brain: glucose and lactate metabolism modulation by ascorbic acid. J Neurochem.,110(2),423-440.

Emerit, J. \& Edeas, M. (2005) Neurodegenerative diseases and oxidative stress. Eur. Neuropsychopharmacol., 15, 100-101.

FCC (Federal Communication Commission). (2000) Commission's Rules to Create a Wireless Medical Telemetry Service; FCC : Washington, DC, USA. FCC 00-211, 1-24.

Fillenz, M.; Lowry, J.P.; Boutelle, M.G.; Fray, A.E. (1999) The role of astrocytes and noradrenaline in neuronal glucose metabolism. Acta Physiol. Scand., 167, 275-284. 
Fillenz, M. (2005) The role of lactate in brain metabolism. Neurochem. Int., 47, 413-417.

Hediger, M.A. (2002) New view at C. Nat. Med., 8, 445-446.

Leuher, D.C. (1983) Overview of biomedical telemetry techniques. Eng. Med. Biol., 3, 17-24.

Lowry, J.P.; Miele, M.; O’Neill, R.D.; Boutelle, M.G.; Fillenz, M. (1998) An amperometric glucose oxidase/poly(o-phenylenediamine) biosensor for monitoring brain extracellular glucose: In vivo characterisation in the striatum striatum of freelymoving rats. J. Neurosci. Methods, 79, 65-74.

Magistretti, P.J.; Pellerin, L.; Rothman, D.L.; Shulman, R.G. (1999) Energy on demand. Science, 283, 496-497.

McMahon C.P.; Rocchitta G.; Serra P.A.; Kirwan S.M.; Lowry J.P.; O'Neill R.D. (2006) The efficiency of immobilised glutamate oxidase decreases with surface enzyme loading: an electrostatic effect, and reversal by a polycation significantly enhances biosensor sensitivity. Analyst, 131(1), 68-72.

Miele, M.; Mura, M.A.; Enrico, P.; Esposito, G.; Serra, P.A.; Migheli, R.; Zangani, D.; Miele, E.; Desole, M.S. (2000) On the mechanism of d-amphetamine-induced changes in glutamate, ascorbic acid and uric acid release in the striatum of freely-moving rats. Br. J. Pharmacol., 129, 582-588.

Pagnacco, G.; Oggero, E.; Morr, D.R.; Berme, N. (1997) Oversampling data acquisition to improve resolution of digitized signals. Biomed. Sci. Instrum., 34, 137-142.

Pantano, P. \& Kuhr, W.G. (1995) Electroanalysis, 7, 405.

Paxinos, G. \& Watson, C. (2007) The Rat Brain in Stereotaxic Coordinates, 6th Ed.; Academic Press: San Diego, CA, USA.

Rice, M.E. (2000) Ascorbate regulation and its neuroprotective role in the brain. Trends Neurosci., 23, 209-216.

Rocchitta, G.; Migheli, R.; Dedola, S.; Calia, G.; Desole, M.S.; Miele, E.; Lowry, J.P.; O’Neill, R.D.; Serra, P.A. (2007) Development of a distributed, fully automated, bidirectional telemetry system for amperometric microsensor and biosensor applications. Sens. Actuat. B, 126, 700-709.

Scheller, F. W.; Schubert, F.; Fedrowitz, J. (1997) Present state and frontiers in biosensorics. EXS, 80, 1-9.

Schuvailo, O.M.; Soldatkin O.O.; Lefebvre, A.; Cespuglio, R.; Soldatkin, A.P. (2006) Highly selective microbiosensors for in vivo measurement of glucose, lactate and glutamate. Analytica Chimica Acta, 573, 110-116

Serra, P.A.; Sciola, L.; Delogu, M.R.; Spano, A.; Monaco, G.; Miele, E.; Rocchitta, G.; Miele, M.; Migheli, R.; Desole, M.S. (2002) The neurotoxin 1-methyl-4-phenyl-1,2,3,6tetrahydropyridine induces apoptosis in mouse nigrostriatal glia. Relevance to nigral neuronal death and striatal neurochemical changes. J Biol Chem., 277, 34451-34461.

Serra, P.A.; Rocchitta, G.; Bazzu, G.; Manca, A.; Puggioni, G.M.; Lowry, J.P.; O’Neill, R.D. (2007) Design and construction of a low cost single-supply embedded telemetry system for amperometric biosensor applications. Sens. Actuat B, 122, 118-126.

Watanabe, Y.; Hyllbrant, B.B.; Langstrom, B. (1997) Tracing oxygen metabolism by use of positron emitter Oxygen-15. Biochem. Biophys. Res. Commun., 231, 131-134.

Wilson, R. \& Turner, A.P.F. (1992) Glucose oxidase: an ideal enzyme. Biosens. Bioelectron., 7, 165-185.

Wolfensohn, S. \& Lloyd, M. (2003) Handbook of Laboratory Animal Management and Welfare, 3rd Ed.; Blackwell Publishing: Cornwall, ON, Canada.

Zhou, R.J; Hao, Z.Q. (2002) The present status and development of biotelemetry. Zhongguo Yi Liao Qi Xie Za Zhi, 26, 212-214. 


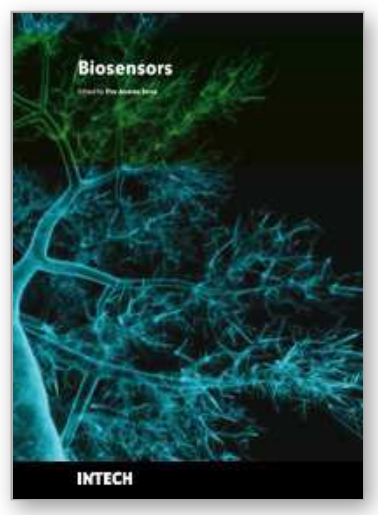

\author{
Biosensors \\ Edited by Pier Andrea Serra
}

ISBN 978-953-7619-99-2

Hard cover, 302 pages

Publisher InTech

Published online 01, February, 2010

Published in print edition February, 2010

A biosensor is defined as a detecting device that combines a transducer with a biologically sensitive and selective component. When a specific target molecule interacts with the biological component, a signal is produced, at transducer level, proportional to the concentration of the substance. Therefore biosensors can measure compounds present in the environment, chemical processes, food and human body at low cost if compared with traditional analytical techniques. Bringing together researchers from 11 different countries, this book covers a wide range of aspects and issues related to biosensor technology, such as biosensor applications in the fields of drug discovery, diagnostics and bacteria detection, optical biosensors, biotelemetry and algorithms applied to biosensing.

\title{
How to reference
}

In order to correctly reference this scholarly work, feel free to copy and paste the following:

Pier Andrea Serra, Giulia Puggioni, Gianfranco Bazzu, Giammario Calia, Rossana Migheli and Gaia Rocchitta (2010). Design and Construction of a Distributed Sensor NET for Biotelemetric Monitoring of Brain Energetic Metabolism Using Microsensors and Biosensors, Biosensors, Pier Andrea Serra (Ed.), ISBN: 978-953-761999-2, InTech, Available from: http://www.intechopen.com/books/biosensors/design-and-construction-of-adistributed-sensor-net-for-biotelemetric-monitoring-of-brain-energetic-

\section{INTECH}

open science | open minds

\author{
InTech Europe \\ University Campus STeP Ri \\ Slavka Krautzeka 83/A \\ 51000 Rijeka, Croatia \\ Phone: +385 (51) 770447 \\ Fax: +385 (51) 686166 \\ www.intechopen.com
}

\author{
InTech China \\ Unit 405, Office Block, Hotel Equatorial Shanghai \\ No.65, Yan An Road (West), Shanghai, 200040, China \\ 中国上海市延安西路65号上海国际贵都大饭店办公楼405单元 \\ Phone: +86-21-62489820 \\ Fax: +86-21-62489821
}


(C) 2010 The Author(s). Licensee IntechOpen. This chapter is distributed under the terms of the Creative Commons Attribution-NonCommercialShareAlike-3.0 License, which permits use, distribution and reproduction for non-commercial purposes, provided the original is properly cited and derivative works building on this content are distributed under the same license. 